\title{
Making leaps in amphibian ecotoxicology: translating individual-level effects of contaminants to population viability
}

\author{
J. D. Willson, ${ }^{1,3}$ W. A. Hopkins, ${ }^{1}$ C. M. Bergeron, ${ }^{1}$ And B. D. Todd ${ }^{1,2}$ \\ ${ }^{1}$ Department of Fish and Wildlife Conservation, Virginia Tech, 100 Cheatham Hall, Blacksburg, Virginia 24061 USA \\ ${ }^{2}$ University of California-Davis, Department of Wildife, Fish, and Conservation Biology, One Shields Avenue, \\ Davis, California 95616 USA
}

\begin{abstract}
Concern that environmental contaminants contribute to global amphibian population declines has prompted extensive experimental investigation, but individual-level experimental results have seldom been translated to population-level processes. We used our research on the effects of mercury $(\mathrm{Hg}$ ) on American toads (Bufo americanus) as a model for bridging the gap between individual-level contaminant effects and amphibian population viability. We synthesized the results of previous field and laboratory studies examining effects of $\mathrm{Hg}$ throughout the life cycle of $B$. americanus and constructed a comprehensive demographic population model to evaluate the consequences of $\mathrm{Hg}$ exposure on population dynamics. Our model explicitly considered density-dependent larval survival, which is known to be an important driver of amphibian population dynamics, and incorporated two important factors that have seldom been considered in previous amphibian modeling studies: environmental stochasticity and sublethal effects. We demonstrated that decreases in embryonic survival and sublethal effects (e.g., reduced body size) that delay maturation have minor effects on population dynamics, whereas contaminant effects that reduce late-larval or post-metamorphic survival have important population-level consequences. We found that excessive $\mathrm{Hg}$ exposure through maternal transfer or larval diet, alone, had minor effects on $B$. americanus populations. Simultaneous maternal and dietary exposure resulted in reduced population size and a dramatic increase in extinction probability, but explicit prediction of population-level effects was dependent on the strength of larval density dependence. Our results suggest that environmental contaminants can influence amphibian population viability, but that highly integrative approaches are needed to translate individual-level effects to populations.
\end{abstract}

Key words: amphibian declines; Bufo americanus; complex life cycles; mercury; pollution; population models; sublethal effects.

\section{INTRODUCTION}

Much of modern ecological research is aimed at understanding and ameliorating anthropogenic impacts on the environment. Although the ultimate goal of these investigations is generally to conserve populations, species, communities, or even ecosystems, the explanatory power of experimentation favors reductionistic approaches that measure effects at lower levels of biological organization (e.g., individual organism, tissue, or subcellular levels). The problematic dichotomy between the biological unit most amenable to experimental research and the unit where inference is ultimately desired has hampered our ability to address a variety of ecological threats. For example, many studies evaluating the detrimental effects of environmental contaminants have relied on standard toxicological methods that measure effects on individual

Manuscript received 19 May 2011; revised 20 January 2012; accepted 13 March 2012. Corresponding Editor: T. W. J. Garner.

${ }^{3}$ E-mail: willsonj@vt.edu organisms (Cairns and Pratt 1993, Clements and Kiffney 1994, Stark 2005). Long-standing recognition of the limitations of this approach (Cairns 1984, 1986, Kimball and Levin 1985) prompted several studies that used integrative methods to bridge the gap between individual-level effects of environmental contaminants and population-level processes (e.g., Forbes and Calow 2002, Tanaka 2003, Miller and Ankley 2004, Lin et al. 2005), but this approach has seldom been applied to terrestrial vertebrates (but see Nakamaru et al. 2002, 2003, Karraker et al. 2008, Salice et al. 2011).

Amphibian ecotoxicology provides an example of the difficulty associated with translating experimental results to the conservation of populations or species. Concern that environmental contaminants may be important contributors to global amphibian population declines prompted extensive experimental investigation of contaminant effects in a variety of amphibian taxa (Alford 2010). Most early studies evaluated acute effects on amphibian embryos and larvae under controlled laboratory conditions (Linder and Grillitsch 2000, Boone and Bridges 2003). Subsequent studies broadened 
the focus of amphibian ecotoxicology to include other ecologically relevant endpoints (e.g., sublethal effects) and used mesocosms or artificial ponds to increase ecological realism, but still generally measured effects at the individual level (Boone and Bridges 2003, Alford 2010). These studies demonstrated that contaminants can have a broad array of adverse effects on larval amphibians, and these effects may interact with a variety of biotic (e.g., presence of predators, or conspecific or heterospecific competitors) and abiotic (e.g., hydroperiod, temperature) factors. However, links between individual-level effects observed in experiments and population dynamics have remained tenuous, complicating our ability to effectively conserve amphibian populations or species (Schmidt 2004). The disconnect between experimental results and population dynamics is particularly troubling in light of the characteristically complex dynamics of amphibian populations, owing in part to their complex life cycles and sensitivity to environmental stochasticity (Pechmann et al. 1991, Semlitsch et al. 1996, Schmidt 2004).

Population models provide a powerful tool for interpreting how alterations of stage-specific vital rates affect population dynamics (McPeek and Peckarsky 1998, Caswell 2001). The utility of models to mechanistically link individual-level contaminant effects to population dynamics has been recognized (Sibly 1996, Forbes and Calow 2002, Hopkins and Rowe 2010, Iwasaki et al. 2010) and this approach has been used to evaluate some amphibian threats, such as elevated embryonic mortality due to ultraviolet radiation (Vonesh and De la Cruz 2002) and terrestrial habitat loss (Trenham and Shaffer 2005, Harper et al. 2008). Recently, Karraker et al. (2008) used population models to demonstrate that lethal effects of road de-icing agents on embryos and larvae can reduce population densities of wood frogs (Rana sylvatica) and spotted salamanders (Ambystoma maculatum) breeding in roadside wetlands. However, theoretical frameworks for extrapolating the individual-level contaminant effects observed in experimental studies to amphibian population viability remain limited. For example, prior models for the effects of contaminants on amphibians have not considered ways in which sublethal effects of contaminants (e.g., reduced body size) may influence populations and few have developed methods to incorporate variation in recruitment due to precipitation or other forms of environmental stochasticity (Salice et al. 2011).

In this study, we used our research on the effects of mercury $(\mathrm{Hg})$ on toads as a model for bridging the gap between individual-level effects of environmental contaminants and amphibian population dynamics. We synthesized the published results of field surveys and extensive laboratory, mesocosm, and terrestrial enclosure experiments that examined the effects of maternal and dietary $\mathrm{Hg}$ acting throughout the life cycle of a widespread amphibian species with a stereotypical anuran life history, the American toad (Bufo ameri- canus). We constructed a demographic population model for $B$. americanus, allowing us to evaluate the consequences of lethal and sublethal effects of $\mathrm{Hg}$ on population dynamics in the context of important natural population drivers including density-dependent larval survival and environmental stochasticity. Specifically, we examined the sensitivity of population dynamics to shifts in parameters that may be affected by $\mathrm{Hg}$ (e.g., stage-specific survival, clutch size, and maturation rates) to assess how effects of contaminants on individual amphibians influence population viability. Finally, we parameterized the model to comprehensively evaluate the effects of $\mathrm{Hg}$ on B. americanus population dynamics under several realistic exposure scenarios.

\section{Methods \\ Background on individual-level effects of $\mathrm{Hg}$ on Bufo americanus}

The American toad (Bufo americanus) is one of the most common and widespread amphibians in eastern North America. Congeners with similar life histories are found throughout the United States and in many temperate and tropical regions world-wide. Bufo americanus exhibits a stereotypical anuran life history, with adults living terrestrially in diverse habitats and breeding explosively in the spring in a variety of aquatic habitats, particularly fish-free, often ephemeral, pools. Females lay large clutches of eggs (2000-20 000; Green 2005), resulting in high larval densities and strong intraspecific interactions within the larval habitat (Brockelman 1969, Wilbur 1977). Larvae mature rapidly, metamorphosing in 50-60 days and rapidly dispersing into the surrounding terrestrial environment.

Our studies on B. americanus have focused on mercury $(\mathrm{Hg})$, an environmental contaminant of global concern due to its ubiquity, toxicity, and ability to bioaccumulate in animal tissues (Mason et al. 1996, Fitzgerald et al. 1998). Exposure to high levels of $\mathrm{Hg}$ can result in acute toxicity and death in humans and wildlife, but the neurotoxic, teratogenic, and endocrine-disrupting nature of $\mathrm{Hg}$ can also induce subtle effects on growth, behavior, and reproduction following exposure to sublethal Hg concentrations (Weiner and Spry 1996, Scheuhammer et al. 2007, Crump and Trudeau 2009, Tan et al. 2009). Though diet is often considered the primary pathway for $\mathrm{Hg}$ exposure, female amphibians may also pass bioaccumulative contaminants, including $\mathrm{Hg}$, to their offspring through maternal transfer, resulting in adverse effects (Hopkins et al. 2006, Bergeron et al. 2010a, 2011b).

Our previous studies of the individual-level effects of maternal and dietary $\mathrm{Hg}$ on Bufo americanus were based primarily on a historically contaminated site along the South River, Virginia, USA (Carter 1977, Eggleston 2009, Bergeron et al. 2010a, b). Field surveys along the extensive $\mathrm{Hg}$ contamination gradient at the South River demonstrated that (1) B. americanus inhabiting the contaminated floodplain bioaccumulate $\mathrm{Hg}$ in their 
TABLE 1. Individual-level effects of maternally transferred and dietary mercury $(\mathrm{Hg})$ on stage-specific vital rates in Bufo americanus.

\begin{tabular}{|c|c|c|c|c|c|c|}
\hline $\mathrm{Hg}$ exposure route & $\begin{array}{l}\text { Clutch } \\
\text { size }\end{array}$ & $\begin{array}{c}\text { Embryo } \\
\text { viability (\%) }\end{array}$ & $\begin{array}{c}\text { Larval } \\
\text { survival (\%) }\end{array}$ & $\begin{array}{c}\text { Larval } \\
\text { growth (\%) }\end{array}$ & $\begin{array}{l}\text { Juvenile } \\
\text { survival }\end{array}$ & $\begin{array}{c}\text { Juvenile } \\
\text { growth (\%) }\end{array}$ \\
\hline Larval diet & & & NE & $-26 \dagger$ & $\mathrm{NE}$ & $\mathrm{NE}$ \\
\hline Maternal & $\mathrm{NE}$ & $-20 \%$ & NE & $-18 \dagger$ & $\mathrm{NE}$ & -7 \\
\hline Maternal + larval diet & $\mathrm{NE}$ & $-20 \%$ & $-50 \S$ & -20 to $-27 \dagger$ & $\mathrm{NE}$ & -7 \\
\hline
\end{tabular}

Notes: Values represent the percentage deviation from reference treatments. Situations where Hg treatments did not differ from reference treatments are denoted NE, and embryos (clutch size and embryo viability) are not exposed to Hg via larval diet. Embryo viability incorporates both hatching success and frequency of larval abnormalities. Results are synthesized from Bergeron et al. $(2010 a, b, 2011 a, b)$ and Todd et al. (2011a, b, 2012).

$\dagger$ Dependent on food rations (Bergeron et al. 2011b, Todd et al. 2011b).

\$ Three-year average (Bergeron 2011).

$\S$ Additional mortality at metamorphic climax under limited food rations (Bergeron et al. 2011b, Todd et al. 2011b).

tissues, with adults exhibiting mean $\mathrm{Hg}$ concentrations 3.5-fold higher than those observed upstream of the $\mathrm{Hg}$ point source (Bergeron et al. 2010b); (2) females maternally transfer $\mathrm{Hg}$ to their offspring (Bergeron et al. 2010a); and (3) larvae developing within contaminated floodplain breeding habitats accumulate additional $\mathrm{Hg}$, resulting in fourfold higher $\mathrm{Hg}$ concentrations than larvae from reference sites (Bergeron et al. 2010b). Because adult $B$. americanus may migrate up to $1 \mathrm{~km}$ between feeding and breeding sites (Forester et al. 2006), contaminated females may oviposit in either contaminated (within the floodplain) or uncontaminated (outside the floodplain) breeding pools. Alternatively, uncontaminated females living outside the floodplain may enter the floodplain to breed. Thus, there is the potential for B. americanus along the South River to be exposed to $\mathrm{Hg}$ through either maternal transfer, larval diet, or both pathways simultaneously (Bergeron et al. 2011b).

Previously, we used a pluralistic combination of field surveys and factorial laboratory, mesocosm, and terrestrial enclosure experiments to systematically evaluate the individual and interactive effects of maternal and larval dietary $\mathrm{Hg}$ throughout the life cycle of $B$. americanus. In our experiments, "Hg-exposed" treatments were representative of animals from contaminated field sites at the high end of the $\mathrm{Hg}$ contamination gradient present at the South River. Specifically, maternal $\mathrm{Hg}$ treatment groups included young from females with $>1.00 \mu \mathrm{g} / \mathrm{g}$ wet mass, blood $\mathrm{Hg}$, whereas reference females contained $<0.25 \mu \mathrm{g} / \mathrm{g}$ blood $\mathrm{Hg}$, resulting in mean egg $\mathrm{Hg}$ concentrations of $0.15 \pm 0.018 \mu \mathrm{g} / \mathrm{g}$, and $0.02 \pm 0.001$ $\mu \mathrm{g} / \mathrm{g}$ dry mass, for maternal $\mathrm{Hg}$ and reference treatments, respectively (mean $\pm \mathrm{SE}$ ). Larvae in dietary $\mathrm{Hg}$ treatments were fed an experimental diet containing 10 $\mu \mathrm{g} \mathrm{Hg} / \mathrm{g}$ dry mass, resulting in body $\mathrm{Hg}$ concentrations of $1.79 \pm 0.13 \mu \mathrm{g} \mathrm{Hg} / \mathrm{g}$ dry mass at completion of metamorphosis (Bergeron et al. 2011b). These $\mathrm{Hg}$ concentrations are comparable to those found in larvae collected from contaminated field sites at the South River $(2.13 \pm 0.60 \mu \mathrm{g} \mathrm{Hg} / \mathrm{g}$ dry mass; Bergeron et al. 2010b). Larvae from reference treatments accumulated $0.051 \pm 0.001 \mu \mathrm{g} \mathrm{Hg} / \mathrm{g}$ dry mass, by the time they completed metamorphosis (Bergeron et al. 2011b).
The results of our previous experiments, as they bear on parameters used to model B. americanus population dynamics in this study, are summarized in Table 1. Generally, maternal transfer of $\mathrm{Hg}$ resulted in more severe effects on offspring than did exposure through larval diet, including a $20 \%$ average reduction in viability of embryos laid by $\mathrm{Hg}$ exposed females. Exposure through either maternal transfer or larval diet, alone, produced a wide array of sublethal effects, particularly reductions in body size of larvae and juveniles, but only maternal effects on body size persisted in terrestrial juveniles (Todd et al. 2012). Exposure to high concentrations of dietary $\mathrm{Hg}$ had no effect on larval survival to metamorphosis. Larvae that received both maternal and dietary $\mathrm{Hg}$ experienced a dramatic (50\%) reduction in survival when larvae were reared individually on a limited food ration (Bergeron et al. 2011b), but this effect was not observed when larvae were raised communally on a higher food ration (Todd et al. 2011a). Importantly, this mortality occurred primarily at metamorphic climax, negating the potential for compensation due to competitive release from larval density dependence (Bergeron et al. 2011b). We found no effects of $\mathrm{Hg}$ on clutch size of adult females, after correcting for the positive relationship between female body size and clutch size (combined data from multiple experiments; ANCOVA; $N=85$ females; high $\mathrm{Hg}$ vs. reference females; covariate $=\mathrm{SVL} ; F_{1,78}=2.18 ; P=$ 0.14; see Bergeron et al. [2011a] for methodological details).

\section{Bufo americanus demographic population model}

To mechanistically evaluate the population-level effects of $\mathrm{Hg}$ on $B$. americanus we constructed a discrete-time, age-structured, population model, based on a general amphibian population model developed by Vonesh and De la Cruz (2002). Because many amphibian populations are thought to be regulated by density dependence in the larval stage (Brockelman 1969, Wilbur 1980) and are subject to dramatic natural population fluctuations due in part to variability in precipitation that affects the size and hydroperiod of the larval habitat (Pechmann et al. 1991, Semlitsch et al. 1996, Semlitsch 2003), our model also incorporated 
density-dependent larval survival and environmental stochasticity, including periodic catastrophic reproductive failure in years of extreme precipitation.

Female B. americanus in northern Virginia reach sexual maturity at 3-4 years of age (Kalb and Zug 1990). Thus, our model included four age classes: two juvenile age classes (first year, $J_{1}$; second year, $J_{2}$ ), a third-year age class $\left(A_{3}\right)$, of which a proportion $(\rho)$ were reproductively mature, and a mature adult age class $(A)$ incorporating all animals 4 years old or greater, with a sex ratio of $\omega$ and annual reproduction of all adult females. Transitions between juvenile and adult age classes were linked by survival rates of juveniles $\left(\sigma_{\mathrm{J}}\right)$ and adults $\left(\sigma_{\mathrm{A}}\right)$, respectively. Reproductive functions relating the number of adults to the number of one-year-old juveniles incorporated female clutch size $(f)$, and survival of embryos $\left(\sigma_{\mathrm{E}}\right)$, larva $\left(\sigma_{\mathrm{L}, t}\right)$, and newly metamorphosed juveniles up to one year of age $\left(\sigma_{M}\right)$. The model can be expressed as a pre-breeding census in matrix form as follows:

$$
\begin{aligned}
& {\left[\begin{array}{c}
J_{1} \\
J_{2} \\
A_{3} \\
A
\end{array}\right]_{t+1}} \\
& =\left[\begin{array}{cccc}
0 & 0 & \rho \omega f \sigma_{\mathrm{E}} \sigma_{\mathrm{L}, t} \sigma_{\mathrm{M}} & \omega f \sigma_{\mathrm{E}} \sigma_{\mathrm{L}, t} \sigma_{\mathrm{M}} \\
\sigma_{\mathrm{J}} & 0 & 0 & 0 \\
0 & \sigma_{\mathrm{J}} & 0 & 0 \\
0 & 0 & \sigma_{\mathrm{A}} & \sigma_{\mathrm{A}}
\end{array}\right]\left[\begin{array}{c}
J_{1} \\
J_{2} \\
A_{3} \\
A
\end{array}\right]_{t} .
\end{aligned}
$$

Density-dependent intraspecific interactions within the larval habitat are important in regulating amphibian populations, including those of B. americanus (Brockelman 1969, Wilbur 1977, 1980, Semlitsch 2003). We incorporated larval density dependence using a function introduced by Vonesh and De la Cruz (2002) and based upon the Beverton-Holt fisheries recruitment model (Beverton and Holt 1957) and Hassell's (1975) model of intraspecific competition:

$$
\sigma_{\mathrm{L}, t}\left(L_{t}\right)=\frac{\sigma_{\mathrm{Lmax}}}{\left(1+d L_{t}\right)^{\gamma}} .
$$

Eq. 2 determined larval survival at each time step $\left(\sigma_{\mathrm{L}, t}\right)$ based on the maximum larval survival observed at very low density $\left(\sigma_{\text {Lmax }}\right)$, the initial number of newly hatched larvae per meter of shoreline $\left(L_{t}\right)$, the strength of density dependence $(\gamma$, density dependence exponent), and a scaling factor ( $d$, the density-dependence coefficient). Importantly, this function allowed evaluation of various forms of density dependence, ranging from density independent $(\gamma=0)$, to compensatory $(\gamma=1)$, to overcompensatory $(\gamma>1)$, and has been parameterized for B. americanus (Vonesh and De la Cruz 2002).

The most pervasive effect of $\mathrm{Hg}$ we observed, a $50 \%$ reduction in survival of larvae exposed to $\mathrm{Hg}$ through both maternal transfer and larval diet, occurred at metamorphosis when larvae were raised on restricted food rations (Bergeron et al. 2011b). Thus, we modeled the additive effects of high density and $\mathrm{Hg}$ by reducing larval survival by $50 \%$ after calculating survival based on density in years when initial larval density $\left(L_{t}\right)$ exceeded 150 larvae $/ \mathrm{m}$ of shoreline. This density threshold corresponds well with densities at which density-dependent reductions in larval survival have been observed in the field (Brockelman 1969). Additionally, the survival rates we observed (48\%) in reference treatments on the restricted diet (Bergeron et al. $2011 b$ ) are very close to survival rates observed in the field by Brockelman (1969) at a density of 167 larvae/m of shoreline $(45 \%)$.

Despite the importance of larval density dependence in population regulation, dynamics of pond-breeding amphibians are stereotypically erratic, due largely to annual variation in production of newly metamorphosed individuals driven by environmental stochasticity, particularly precipitation (Pechmann et al. 1991, Semlitsch et al. 1996). We incorporated the effects of environmental stochasticity on annual metamorph production by varying the size of the larval habitat $\left(H_{t}\right)$ based on annual spring precipitation data for the region. Thus, at each (yearly) time step, initial larval density $\left(L_{t}\right)$ was a function of the number of breeding adults $\left(A_{t}+\rho A_{3 t}\right)$, the sex ratio $(\omega)$, female clutch size $(f)$, and embryonic survival $\left(\sigma_{\mathrm{E}}\right)$, divided by the size (meters of shoreline) of the larval habitat $\left(H_{t}\right)$, which varied based on annual precipitation:

$$
L_{t}\left(A_{t}, A_{3 t}, H_{t}\right)=\frac{\left(A_{t}+\rho A_{3 t}\right)\left(\omega f \sigma_{\mathrm{E}}\right)}{H_{t}} .
$$

We considered a theoretical $B$. americanus population representative of those present at our primary study site, the floodplain of the South River, Virginia, USA. This population was centered on an ephemeral breeding pool with a mean shoreline length of $100 \mathrm{~m}$, but we varied wetland size around this mean based on empirical precipitation data for the region. Specifically, we obtained yearly cumulative spring (March-June) rainfall data for the Central Mountains region of Virginia from the NOAA National Climatic Data Center for the years 1895-2010. For each yearly projection, we drew randomly from this pool of precipitation values, setting a breeding pool circumference of $100 \mathrm{~m}$ at the mean spring precipitation value $(36.25 \mathrm{~cm})$. Around that mean, we assumed a direct relationship between precipitation and breeding pool size that would produce twice the circumference $(200 \mathrm{~m})$ at the maximum rainfall value of $57.71 \mathrm{~cm}$.

Frequency of catastrophic reproductive failure has not been determined for B. americanus and likely varies considerably among breeding sites. We set the probability of catastrophic failure due to pond drying at 0.15 by fixing larval survival $\left(\sigma_{\mathrm{L}, t}\right)$ at 0 in the $15 \%$ of years with the lowest cumulative spring rainfall $(<27.0 \mathrm{~cm})$. Although not characteristic of all amphibian populations, the location of our study site within a river 
TABLE 2. Parameter values used in the reference (no $\mathrm{Hg}$ effects) model of Bufo americanus population dynamics.

\begin{tabular}{|c|c|c|c|c|}
\hline Parameter & $\begin{array}{l}\text { Range or } \\
95 \% \text { CI }\end{array}$ & Fixed value & $\begin{array}{l}\text { Range explored } \\
\text { in simulations }\end{array}$ & Source(s) \\
\hline Clutch size $(f)$ & $6216-7248$ & 6731 & fixed $\dagger$ & 1,2 \\
\hline Embryonic survival $\left(\sigma_{\mathrm{E}}\right)$ & $0.64-0.77$ & 0.70 & $0-1$ & 1,2 \\
\hline Maximum larval survival $\left(\sigma_{L \max }\right)$ & $0.48-0.71$ & $0.59 \ddagger$ & $0-1$ & 3 \\
\hline Density-dependent coefficient $(d)$ & $0.005-0.01$ & 0.007 & fixed & $4 \S$ \\
\hline Density-dependent exponent $(\gamma)$ & $0.76-1.26$ & 1 & $0.76-1.26$ & $4 \S$ \\
\hline Fist year juvenile survival $\left(\sigma_{M}\right)$ & $0-0.32$ - & 0.2 & $0-1$ & $4,5,6,7$ \\
\hline Second and third year juvenile survival $\left(\sigma_{\mathrm{J}}\right)$ & $0.18-0.35 \#$ & 0.2 & $0-1$ & $4,6,7$ \\
\hline Adult survival $\left(\sigma_{\mathrm{A}}\right)$ & $0.11-0.58$ & 0.6 & $0-1$ & 8,9 \\
\hline Proportion mature at age $3(\rho)$ & $>0$ & 0.5 & $0-1$ & $10,11,12$ \\
\hline
\end{tabular}

Sources: 1, Bergeron (2011); 2, Bergeron et al. (2011a); 3, Todd et al. (2011a); 4, Vonesh and De la Cruz (2002); 5, Todd et al. (2012); 6, Clarke (1977); 7, Biek et al. (2002); 8, Schmidt and Anholt (1999); 9, Schmidt et al. (2002); 10, Hamilton (1934); 11, Acker et al. (1986); 12, Kalb and Zug (1990).

$\dagger$ Not varied in analyses, but result would be identical to varying embryonic survival $\left(\sigma_{\mathrm{E}}\right)$.

$\$$ Based on uncontaminated larvae raised at low density in mesocosms with predators.

$\S$ Based on a meta-analysis of Brockelman (1969) and Wilbur (1977).

- Multiple Bufo species.

\# B. fowleri and B. canorus.

$\|$ B. bufo.

floodplain necessitated consideration of additional catastrophic reproductive failure due to flood events. Floods can result in substantial surface flow within the floodplain, washing out $B$. americanus breeding pools and likely killing or displacing larvae far downstream in areas inhabited by fish and other predators. We calculated the frequency of flooding by examining hydrological data from the South River at Lynnwood, Virginia from 1930-2010 (USGS National Water Information System; data available online). ${ }^{4}$ Over this period, the river exceeded flood stage during March-June in $6(7.5 \%)$ years. Thus, we also fixed larval survival $\left(\sigma_{\mathrm{L}, t}\right)$ at 0 in the $7.5 \%$ of years with the highest cumulative spring rainfall $(>46.2 \mathrm{~cm})$. Our cumulative frequency of catastrophic reproductive failure $(22.5 \%)$ is likely typical of many amphibian breeding habitats in the southeastern United States. For example, in a 16-year amphibian study at a wellstudied seasonal wetland in South Carolina, $25 \%$ of years were characterized as having a short hydroperiod, when most amphibian species suffered complete or near complete reproductive failure (Semlitsch et al. 1996).

We parameterized our reference (no $\mathrm{Hg}$ effects) model using demographic data from our own studies of B. americanus or the literature (Table 2). We considered both males and females in our model, due to the need to include males when calculating larval density. However, because females are most important to population dynamics, we used female-specific estimates for post-metamorphic parameters, when possible, and assumed a 1:1 offspring sex ratio by setting $\omega=0.5$. Published data on survival of terrestrial juvenile toads are sparse because juveniles do not congregate at breeding sites where censuses typically occur. Therefore, we assumed that survival

4 waterdata.usgs.gov of juvenile toads from age 1 to age 2 and age 2 to age $3\left(\sigma_{\mathrm{J}}\right)$ was equal to survival of first-year juveniles $\left(\sigma_{M}\right)$ and survival of young adults from age 3 to age 4 was equal to adult survival. All models were constructed and run in program $\mathrm{R}$ ( $\mathrm{R}$ Foundation for Statistical Computing, Vienna, Austria).

\section{Model sensitivity}

Before quantitatively evaluating $\mathrm{Hg}$ effects, we first conducted simulations examining the overall sensitivity of population dynamics to large shifts in individual vital rates that may be affected by $\mathrm{Hg}$ exposure. Specifically, we varied stage-specific parameters (embryonic viability $\left[\sigma_{\mathrm{E}}\right]$, additional decreases in larval survival at metamorphosis, maturation probability at age $3[\rho]$, survival of first-year terrestrial juveniles $\left[\sigma_{\mathrm{M}}\right]$, and adult survival $\left.\left[\sigma_{\mathrm{A}}\right]\right)$ individually from 0 to 1 , while holding other parameters constant, and monitored proportional shifts in mean annual adult population size and quasi-extinction probability over 200 projected years. We set a quasi-extinction threshold at 10 adult individuals, and ran 5000 simulations for each parameter combination, beginning with an initial population vector $\left[107 \mathrm{~A}, 91 A_{3}\right.$, $\left.457 J_{2}, 2287 J_{1}\right]$ representing the equilibrium values for each age class when the reference model (no $\mathrm{Hg}$ effects) was run at mean values of $\gamma(1)$ and $H(100)$. Because the strength of larval density dependence strongly influences amphibian population dynamics (Brockelman 1969, Wilbur 1977, 1980, Vonesh and De la Cruz 2002), but has seldom been quantified in the field, we evaluated sensitivity of population dynamics to shifts in each parameter across the $95 \%$ confidence interval for strength of density dependence $(\gamma=0.76$ 1.26) previously identified by Vonesh and De la Cruz (2002) from a meta-analysis of density-dependent effects in B. americanus. 


\section{Evaluating effects of maternally transferred and dietary $\mathrm{Hg}$ on population dynamics}

We used model simulations to explicitly examine effects of $\mathrm{Hg}$ on $\mathrm{B}$. americanus population viability under several relevant scenarios of $\mathrm{Hg}$ exposure: (1) reference population exposed only to background levels of $\mathrm{Hg}$, (2) excessive exposure to $\mathrm{Hg}$ through maternal transfer, (3) excessive exposure to $\mathrm{Hg}$ through larval diet, and (4) combined excessive exposure to $\mathrm{Hg}$ through both maternal transfer and larval diet. For each scenario, we adjusted survival parameters based on all observed effects of $\mathrm{Hg}$ on survival or embryonic viability (Table 1). Because the most pervasive sublethal $\mathrm{Hg}$ effects we observed were reductions in larval and juvenile body size, and because smaller size at metamorphosis can delay maturation (Berven 1990, Scott 1994), we incorporated this sublethal effect by reducing the proportion of female B. americanus that matured at age three vs. age four $(\rho)$ by the observed reduction in growth rate. For these initial simulations, we assumed that sublethal reductions in body size had no positive or negative effect on other post-metamorphic individuals in the population. Although we did not examine the effects of $\mathrm{Hg}$ on survival of adult $B$. americanus in our experimental work, $\mathrm{Hg}$ can affect survival or performance of adult animals (Scheuhammer et al. 2007), including amphibians (Burke et al. 2010). Although not detected in our studies (Todd et al. 2012), reduced adult survival could also result from sublethal reductions in body size that compromise locomotor performance (John-Alder and Morin 1990), increase vulnerability to predators (Vincent et al. 2006, Willson and Hopkins 2011), or increase desiccation rate (Spight 1968, Wilbur 1980). Thus, we included a final hypothetical scenario that included a small decrease (5\%) in adult survival of animals exposed to both maternal and dietary $\mathrm{Hg}$. As in previous simulations, we evaluated quasi-extinction probability ( $n<10$ adults) over 200 years and mean annual adult population size at each parameter combination across the confidence interval of strength of larval density dependence $(\gamma=0.76-1.26$; Vonesh and De la Cruz 2002).

\section{Results}

\section{Model sensitivity}

Altering embryonic viability had minor effects on adult population size and extinction probability unless viability was very low $\left(\sigma_{\mathrm{E}}<0.2 ;\right.$ Fig. 1$)$. Viability could be reduced substantially from reference levels $(0.7$; Table 2 ) with only minor shifts in adult population size or quasi-extinction probability. However, both adult population size and quasi-extinction risk were sensitive to the strength of larval density dependence $(\gamma)$. Above very low levels of embryonic viability $\left(\sigma_{\mathrm{E}}>0.2\right)$, quasiextinction probability was low $(<0.2)$ if density dependence was weak $(\gamma \leq 1)$; increasing viability resulted in only slight increases in adult population size. If density dependence was strong $(\gamma>1)$, population size was small and quasi-extinction probability was relatively high, but both were insensitive to shifts in embryonic viability.

Population dynamics were sensitive to decreases in larval survival occurring at metamorphic climax that were additive to effects of larval density dependence and were enhanced at high density (Fig. 1). Decreasing survival at metamorphosis decreased population size slightly and increased quasi-extinction probability, but the slopes of those relationships varied with the strength of density dependence. At the average strength of density dependence $(\gamma=1)$ reducing survival at metamorphosis from the reference value of 1 to 0.4 resulted in a gradual decrease in adult population size from 75 to 31 individuals and an increase in quasi-extinction probability from 0.2 to 1 . When density dependence was weak $(\gamma$ $\leq 1$ ), however, the relationship between larval survival and quasi-extinction probability approached a threshold, increasing rapidly from 0 to 1 when survival at metamorphosis dropped below 0.4 .

Population dynamics were highly sensitive to changes in post-metamorphic (juvenile or adult) survival (Fig. 1). Increasing survival of either first year juveniles or adults resulted in substantial increases in adult population size. Quasi-extinction probability exhibited a threshold response to shifts in either juvenile or adult survival and this threshold varied only slightly across the $\gamma$ confidence interval. Quasi-extinction probability was very low until first year survival dropped below 0.3 , but increased dramatically below that value, regardless of the strength of density dependence. The threshold value for adult survival was much higher, with quasiextinction probability rising rapidly from 0 to 1 when adult survival dropped below 0.6.

Similar to embryonic viability, delaying maturity (i.e., reducing the proportion of females breeding at age $3 ; \rho$ ) had little effect on $B$. americanus population dynamics (Fig. 1). At $\gamma=1$, mean adult population size was near 80 and quasi-extinction probability was $<0.2$ for all values of $\rho$. Increasing the strength of density dependence lowered population size and increased quasiextinction probability, but these values were insensitive to $\rho$.

\section{Effects of maternally transferred and dietary $\mathrm{Hg}$ on population dynamics}

The combined individual and interactive effects of $\mathrm{Hg}$ exposure through maternal transfer or larval diet on $B$. americanus population dynamics are shown in Fig. 2. In both reference (model parameterized using data from uncontaminated sites) and $\mathrm{Hg}$-exposed cases, increasing the strength of larval density dependence $(\gamma)$ decreased adult population size and increased quasi-extinction probability. When density dependence was compensatory $(\gamma=1)$, populations not subjected to the effects of $\mathrm{Hg}$ averaged 83 adults and had a $14 \%$ probability of quasi-extinction within 200 years. Exposure to $\mathrm{Hg}$ 

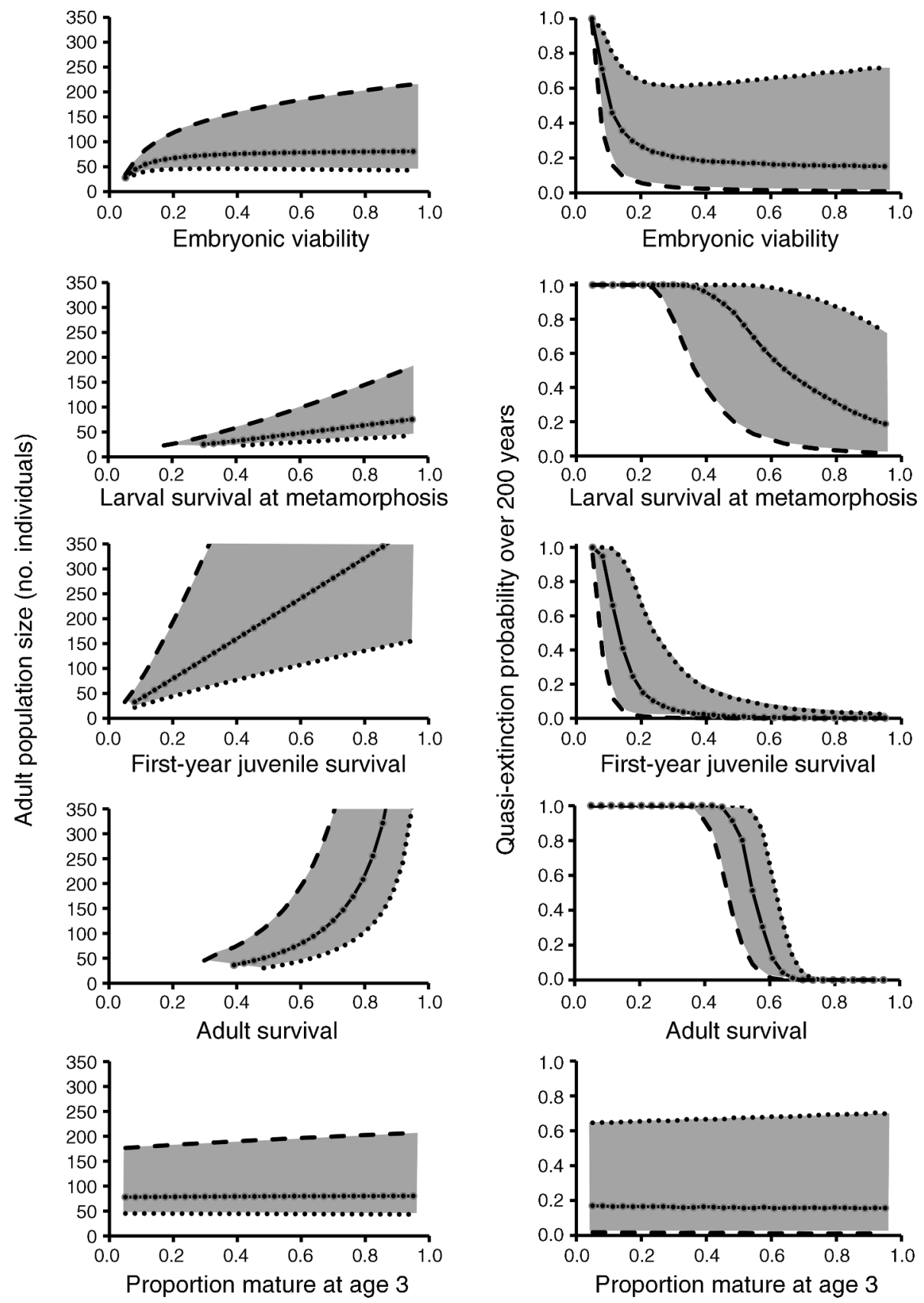

FIG. 1. Sensitivity of Bufo americanus population dynamics to shifts in stage-specific vital rates. Solid isoclines represent mean annual adult population size and quasi-extinction probability as vital rates were varied from 0 to 1 at the mean strength of density dependence $(\gamma=1$; Vonesh and De la Cruz 2002). In each case, sensitivity to larval density dependence is indicated by the shaded region, bounded by the confidence interval for $\gamma(\gamma=1.26$ [dotted isoclines], $\gamma=0.76$ [dashed isoclines]; Vonesh and De la Cruz 2002). Larval survival at metamorphosis refers to additional mortality occurring at metamorphic climax (i.e., after density effects) when larval density was high ( $L_{t}>150 / \mathrm{m}$ of shoreline; see methods). More steeply sloped isoclines indicate stronger sensitivity of population dynamics to shifting vital rates, whereas flatter isoclines indicate relatively insensitive relationships.

through either maternal transfer or larval diet, alone, resulted in decreased embryonic viability or reduced body size (Table 1), the latter of which may translate to delayed maturation probability. Incorporating these effects had very little effect on population dynamics. However, adjusting model parameters to incorporate the interactive effects of maternal and dietary $\mathrm{Hg}$ exposure dramatically reduced adult population size and increased quasi-extinction probability. Specifically, at $\gamma=$ 1 , populations subjected to both maternal and dietary effects of $\mathrm{Hg}$ were $53 \%$ smaller (39 adults) and had a $479 \%$ greater probability of quasi-extinction within 200 

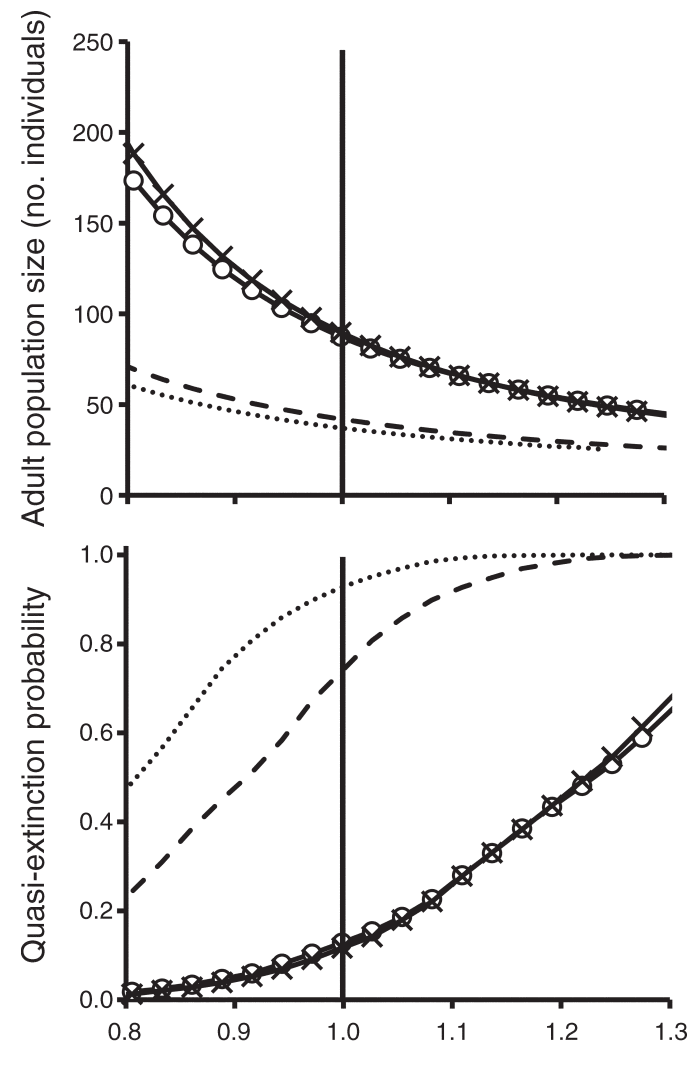

Strength of larval density dependence $(\gamma)$

FIG. 2. Case studies evaluating the individual and interactive effects of $\mathrm{Hg}$ exposure through maternal transfer and larval diet on Bufo americanus population dynamics. We considered cases of no $\mathrm{Hg}$ exposure (solid line), maternal $\mathrm{Hg}$ exposure alone (crosses), exposure to $\mathrm{Hg}$ through larval diet alone (open circles), and combined maternal and dietary exposure (dashed line), by adjusting model parameters based on all observed $\mathrm{Hg}$ effects for each exposure scenario (Table 1). Additionally, we considered a hypothetical case where maternal and dietary $\mathrm{Hg}$ exposure resulted in minor additional adult mortality $(5 \%$ reduction in survival; dotted line). We examined the effects of $\mathrm{Hg}$ exposure on quasi-extinction probability and mean annual adult population size for each case across varying strengths of density dependence $(\gamma ; 95 \%$ CI for B. americanus $=0.76-1.26$; mean $=1$ [solid vertical line]; Vonesh and De la Cruz 2002).

years than reference populations $(81 \%$ vs. $14 \%$, respectively). Adding a hypothetical minor $(5 \%)$ decrease in adult survival in a population exposed to both maternal and dietary $\mathrm{Hg}$ slightly decreased population size and increased quasi-extinction probability to $95 \%$ at $\gamma=1$.

\section{DisCUSSION}

We used a demographic population model to translate experimentally derived individual-level effects of an environmental contaminant to changes in amphibian population dynamics. Overall, exposure to $\mathrm{Hg}$ through maternal transfer or larval diet, alone, had minor effects on population size or extinction probability. This result was not unexpected given that these exposure routes generally affected growth or embryonic viability, and that population dynamics were insensitive to shifts in those parameters. However, we found that elevated mortality at metamorphic climax due to the combination of high maternal and dietary $\mathrm{Hg}$ exposure translated into a dramatic reduction in population size and an increase in quasi-extinction risk. Our results demonstrate that environmental contaminants can have important effects on amphibian populations, but that timing of effects must be evaluated in light of larval density dependence to infer population-level effects.

Although our model was tailored to examine effects of $\mathrm{Hg}$, our analyses revealed general patterns of sensitivity that agree well with those identified using more general models (Biek et al. 2002, Vonesh and De la Cruz 2002, Trenham and Shaffer 2005). Specifically, our results support the importance of post-metamorphic survival and suggest that perturbation of embryonic parameters has minor consequences for amphibian population dynamics. The insensitivity of population dynamics to embryonic viability arises directly from the high fecundity of female toads; in most years many more eggs are laid than are needed to saturate the larval environment and any loss of embryos is compensated for by increased larval survival due to competitive release (Vonesh and De la Cruz 2002). Importantly, this result held even though we explicitly incorporated environmental stochasticity and catastrophic reproductive failure by varying the size (carrying capacity) of the aquatic habitat based on empirical precipitation data. Our findings support previous warnings that the conservation implications of effects of contaminants on embryonic stages should be interpreted with caution (Biek et al. 2002, Vonesh and De la Cruz 2002, Schmidt 2004) and that knowledge of the strength of larval density dependence is critical to evaluating the severity of these effects (Vonesh and De la Cruz 2002, Karraker et al. 2008).

Evidence that reducing survival of early amphibian life stages (e.g., embryos) has minor effects on population dynamics (Biek et al. 2002, Vonesh and De la Cruz 2002) has cast doubt on the importance of effects of environmental contaminants on amphibian larvae (Schmidt 2004). In contrast, our results demonstrate that lethal effects on amphibian larvae can strongly influence population dynamics but that evaluating the timing of effects in relation to larval density dependence is critical for evaluating population-level impacts. We found that combined exposure to $\mathrm{Hg}$ through both maternal transfer and larval diet resulted in a reduction in B. americanus population size and a dramatic increase in extinction probability. This effect was driven by a $50 \%$ reduction in survival at metamorphic climax under limited food conditions (Bergeron et al. 2011b). Thus, in our case, lethal effects of contaminants acted synergistically with the effects of larval density dependence, resulting in enhanced mortality at high density. Functionally, this affects population dynamics in much the same way as a reduction in survival of terrestrial juveniles. In amphibians, metamorphic climax is a 
period of increased vulnerability for immunological (Todd 2007), energetic (Beck and Congdon 2003), and ecological (Arnold and Wassersug 1978) reasons, and is a time when adverse effects of contaminants frequently manifest (e.g., Marian et al. 1983, Snodgrass et al. 2004, 2005, Unrine et al. 2004). Such effects likely have important population-level consequences in most species. Alternatively, if acute effects occur early in the larval stage, larval mortality may compensate through relaxation of competitive interactions, provided sufficient larvae remain to saturate the aquatic habitat (Rohr et al. 2006). Because effects that manifest late in the larval stage or at metamorphic climax have a much higher impact on population dynamics than effects manifesting early in development, bioassays that extend through metamorphosis (e.g., Gutleb et al. 2007) may provide more relevant indications of effects that may influence population dynamics than assays focusing on embryonic viability and early larval development.

Demographic population models provide a framework for evaluating how sublethal effects can influence population dynamics (McPeek and Peckarsky 1998). Although sublethal effects of environmental contaminants have been postulated to influence amphibians population viability (Boone and Bridges 2003, Todd et al. 2012), sublethal effects have not been explicitly incorporated in previous ecotoxicological modeling studies. The most pervasive sublethal effects of $\mathrm{Hg}$ we observed were reductions in larval and juvenile body size. Because smaller size at metamorphosis can delay maturation (Berven 1990, Scott 1994), we incorporated this sublethal effect by reducing the proportion of female $B$. americanus that matured at age three vs. age four. Somewhat surprisingly, we found that delaying maturation by up to one year had little effect on adult population size or extinction probability. When evaluated from a theoretical perspective, however, the explanation for this result becomes clear. The proximate result of decreasing maturation probability is a reduction in the number of breeding females and thus the total number of eggs produced each year. Functionally, this reduction in egg production is analogous to reducing embryonic viability, except that the presence of older females prevents egg production from dropping below the threshold at which population declines occur (Fig. 1). A similar result would be expected if sublethal effects on body size resulted in reduced clutch sizes (Berven 1988), which would also result in a net reduction in annual egg production. These results suggest that as with embryonic viability, sublethal effects on body size or maturation rate should be interpreted with caution, especially in relatively long-lived species with strong larval density dependence. However, it is important to remember that although we saw no effects of $\mathrm{Hg}$ or body size on survival of juvenile toads housed in terrestrial mesocosms (Todd et al. 2012), these effects may ultimately have a greater influence on survival under completely natural conditions. For example, large body size may directly reduce desiccation rate (Spight 1968, Wilbur 1980), predation by gape-limited predators (Vincent et al. 2006), or may indirectly facilitate dispersal or predator evasion through enhanced locomotor performance and stamina (John-Alder and Morin 1990). Given the sensitivity of population dynamics to limited (e.g., 5\%; Fig. 2) additional post-metamorphic mortality, even minor reductions in survival resulting from smaller body size may have strong effects on populations. Although our study is among the first to explicitly translate sublethal effects of contaminants to population dynamics, individual-based population models (e.g., Taylor and Scott 1997, Taylor et al. 2006) may provide an alternative method for evaluating how more complex sublethal effects of contaminants influence amphibian populations.

Although our results suggest that combined exposure to maternal and dietary $\mathrm{Hg}$ strongly affects toad population dynamics, they also generate optimism that such effects can be mitigated through environmental restoration. Because reductions in survival at metamorphosis were only evident when individuals were exposed to high $\mathrm{Hg}$ concentrations through both trophic and maternal pathways (Bergeron et al. 2011b), reducing exposure through either route would alleviate most population-level effects. Reducing $\mathrm{Hg}$ exposure through larval diet may provide the most realistic target for remediation because amphibian breeding habitats are often small, discrete, and can be artificially constructed for some species (Shulse et al. 2010). Our results suggest that if $\mathrm{Hg}$ contamination can be reduced within breeding habitats, or if uncontaminated alternative breeding sites can be created nearby, population-level effects of $\mathrm{Hg}$ might be reduced, even if adults continue to accumulate $\mathrm{Hg}$ in terrestrial habitats and pass it to offspring though maternal transfer (Bergeron et al. 2010a).

Our highly integrative research on the effects of $\mathrm{Hg}$ on Bufo americanus provides a model for bridging the gap between individual-level effects of environmental contaminants and population dynamics in amphibians. Because sensitivity of population dynamics to perturbations in stage-specific vital rates are generally similar among organisms with similar life histories (Heppell et al. 2000) our results can be used to qualitatively assess the risks that environmental contaminants pose to other amphibians with similar life histories, such as many anurans. However, it is important to recognize that contaminant effects may vary among species (Cairns 1986). Applying our approach to other contaminants or species will require systematic experimental evaluation of effects of contaminants acting at various life stages as well as comprehensive life-history data from reference populations with which to inform models (Hopkins and Rowe 2010). Particularly, our study highlights the importance of understanding larval density dependence when interpreting the population-level consequence of adverse effects on amphibian larvae. Density dependence in larval amphibians is complex, poorly under- 
stood, and likely varies among species and situations (e.g., habitats, environmental conditions, years). Our simulation analyses revealed that the strength of larval density dependence was important in mediating the effects of $\mathrm{Hg}$ on $B$. americanus population dynamics; at any given level of $\mathrm{Hg}$ exposure, effects on population size or extinction probability generally increased in severity with increasing strength of density dependence. Thus, although few studies have explicitly examined interactive effects of density and contaminants in amphibian larvae (but see Boone and Semlitsch 2001, Rohr et al. 2006), understanding these factors is critical for evaluating the population-level consequences of environmental contamination.

Finally, our study has identified several important avenues for future research. A key area of uncertainty in our study lies in our understanding of terrestrial subadult and adult life stages. Although our experimental evaluation of effects of $\mathrm{Hg}$ extended longer than the timeline of most studies (to 1 year post-metamorphosis; Todd et al. 2012), we have not evaluated effects of dietary $\mathrm{Hg}$ on survival of adult toads. Yet, our sensitivity analyses confirmed the importance of adult survival in amphibian population dynamics (Biek et al. 2002, Vonesh and De la Cruz 2002, Schmidt et al. 2005). Indeed, when density dependence was compensatory, incorporating a hypothetical minor reduction in adult survival on top of other effects was sufficient to raise extinction probability of a population exposed to $\mathrm{Hg}$ through both maternal transfer and larval diet to nearly $100 \%$. Thus, while larval life stages may be viable targets for remediation, preservation of sufficient high-quality adult habitat remains critical (Harper et al. 2008) and additional experiments examining effects of contaminants on terrestrial adult amphibians are needed (Hopkins and Rowe 2010). Moreover, because reductions in body size are a common sublethal effect of contaminants (Boone and Bridges 2003) that may persist into terrestrial life stages (Todd et al. 2012), future studies should rigorously evaluate size-specific survival of amphibians in field (e.g., Schmidt et al. 2012). Finally, our study provides a habitat-based framework (Akcakaya 2000) for incorporating environmental stochasticity into models of population-level responses of amphibians to ecological or environmental stressors. This approach could be used to evaluate the interactive effects of climate change and other stressors and could be extended to examine the role that contaminated habitats play in metapopulation or source-sink dynamics resulting from stochastic processes (Akcakaya 2000).

\section{ACKNOWLEDGMENTS}

We thank S. DuRant for providing comments and ideas that improved this manuscript. We thank D. Cristol, A. Condon, J. Schmerfeld, and the South River Science Team for their support. Early discussions with C. Rowe were instrumental in developing the conceptual basis for this project. Financial support was provided by E. I. DuPont de Nemours, Virginia Polytechnic Institute and State University, and by the National Science Foundation (NSF \# IOB-0615361). C. M. Bergeron was supported by the U.S. EPA STAR Graduate Fellowship (FP-9170040-1). EPA has not officially endorsed this publication and the views expressed herein may not reflect the views of the EPA. Research was completed with oversight from the South River Science Team, which is a collaboration of state and federal agencies, academic institutions, and environmental interests.

\section{Literature Cited}

Acker, P. M., K. C. Kruse, and E. B. Krehbiel. 1986. Aging Bufo americanus by skeletochronology. Journal of Herpetology 20:570-574.

Akcakaya, H. R. 2000. Viability analyses with habitat-based metapopulation models. Population Ecology 42:45-53.

Alford, R. A. 2010. Declines and the global status of amphibians. Pages 13-45 in D. Sparling, G. Linder, C. Bishoip, and S. Krest, editors. Ecotoxicology of reptiles and amphibians. SETAC Press, Pensacola, Florida, USA.

Arnold, S. J., and R. J. Wassersug. 1978. Differential predation on metamorphic anurans by garter snakes (Thamnophis): social behavior as a possible defense. Ecology 59:1014-1022.

Beck, C. W., and J. D. Congdon. 2003. Energetics of metamorphic climax in the southern toad (Bufo terrestris). Oecologia 137:344-351.

Bergeron, C. M. 2011. Individual and interactive effects of maternally- and trophically-derived mercury on early amphibian development. Dissertation. Virginia Tech University, Blacksburg, Virginia, USA.

Bergeron, C. M., C. M. Bodinof, J. M. Unrine, and W. A. Hopkins. 2010a. Bioaccumulation and maternal transfer of mercury and selenium in amphibians. Environmental Toxicology and Chemistry 29:989-997.

Bergeron, C. M., C. M. Bodinof, J. M. Unrine, and W. A. Hopkins. 2010b. Mercury accumulation along a contamination gradient and nondestructive indices of bioaccumulation in amphibians. Environmental Toxicology and Chemistry 29:980-988.

Bergeron, C. M., W. A. Hopkins, C. M. Bodinof, S. A. Budischak, H. Wada, and J. M. Unrine. 2011a. Counterbalancing effects of maternal mercury exposure during different stages of early ontogeny in American toads. Science of the Total Environment 409:4746-4752.

Bergeron, C. M., W. A. Hopkins, B. D. Todd, M. J. Hepner, and J. M. Unrine. 2011b. Interactive effects of maternal and dietary mercury exposure have latent and lethal consequences for amphibian larvae. Environmental Science and Technology 45:3781-3787.

Berven, K. A. 1988. Factors affecting variation in reproductive traits within a population of wood frogs (Rana sylvatica). Copeia 1988:605-615.

Berven, K. A. 1990. Factors affecting population fluctuations in larval and adult stages of the wood frog (Rana sylvatica). Ecology 71:1599-1608.

Beverton, R. J. H., and S. J. Holt. 1957. On the dynamics of exploited fish populations. Chapman and Hall, London, UK.

Biek, R., W. C. Funk, B. A. Maxell, and L. S. Mills. 2002. What is missing in amphibian decline research: insights from ecological sensitivity analysis. Conservation Biology 16:728734.

Boone, M. D., and C. M. Bridges. 2003. Effects of pesticides on amphibian populations. Pages 152-167 in R. D. Semlitsch, editor. Amphibian conservation. Smithsonian Institution, Washington, D.C., USA.

Boone, M. D., and R. D. Semlitsch. 2001. Interactions of an insecticide with larval density and predation in experimental amphibian communities. Conservation Biology 15:228-238.

Brockelman, W. Y. 1969. An analysis of density effects and predation in Bufo americanus tadpoles. Ecology 50:632-644.

Burke, J. N., C. M. Bergeron, B. D. Todd, and W. A. Hopkins. 2010. Effects of mercury on behavior and performance of 
northern two-lined salamanders (Eurycea bislineata). Environmental Pollution 158:3546-3551.

Cairns, Jr., J. 1984. Are single species toxicity tests alone adequate for estimating environmental hazard? Environmental Monitoring and Assessment 4:259-273.

Cairns, Jr., J. 1986. The myth of the most sensitive species. BioScience 36:670-672.

Cairns, Jr., J., and J. Pratt. 1993. Trends in ecotoxicology. Science of the Total Environment 134(Supplement):7-22.

Carter, L. J. 1977. Chemical plants leave unexpected legacy for two Virginia rivers. Science 198:1015-1020.

Caswell, H. 2001. Matrix population models. Second edition. Sinauer Associates, Sunderland, Massachusetts, USA.

Clarke, R. D. 1977. Postmetamophic survivorship of Fowler's toad, Bufo woodhousei fowleri. Copeia 1977:594-597.

Clements, W. H., and P. M. Kiffney. 1994. Assessing contaminant effects at higher levels of biological organization. Environmental Toxicology and Chemistry 13:357-359.

Crump, K. L., and V. L. Trudeau. 2009. Mercury-induced reproductive impairment in fish. Environmental Toxicology and Chemistry 28:895-907.

Eggleston, J. 2009 Mercury loads in the South River and simulation of mercury total maximum daily loads (TMDLs) for the South River, South Fork Shenandoah River, and Shenandoah River-Shenandoah Valley, Virginia. U.S. Geological Survey Scientific Investigations Report 2009-5076. USGS, Reston, Virginia, USA.

Fitzgerald, W. F., D. R. Engstrom, R. P. Mason, and E. A. Nater. 1998. The case for atmospheric mercury contamination in remote areas. Environmental Science and Technology 32:1-7.

Forbes, V. E., and P. Calow. 2002. Population growth rate as a basis for ecological risk assessment of toxic chemicals. Philosophical Transactions of the Royal Society B 357:1299-1306.

Forester, D. C., J. W. Snodgrass, K. Marsalek, and Z. Lanham. 2006. Post-breeding dispersal and summer home range of female American toads (Bufo americanus). Northeastern Naturalist 13:59-72.

Green, D. M. 2005. Bufo americanus. Pages 386-390 in M. Lanoo, editor. Amphibian declines: the conservation status of United States species. University of California Press, Berkeley, California, USA.

Gutleb, A. C., M. Schriks, L. Mossink, J. H. J. van den Berg, and A. J. Murk. 2007. A synchronized amphibian metamorphosis assay as an improved tool to detect thyroid hormone disturbance by endocrine disruptors and apolar sediment extracts. Chemosphere 70:93-100.

Hamilton, W. J., Jr. 1934. The rate of growth of the toad (Bufo amerianus Holbrook) under natural conditions. Copeia 1934:88-90.

Harper, E. B., T. A. G. Rittenhouse, and R. D. Semlitsch. 2008. Demographic consequences of terrestrial habitat loss for pool-breeding amphibians: predicting extinction risks associated with inadequate size of buffer zones. Conservation Biology 22:1205-1215.

Hassell, M. P. 1975. Density dependence in single species populations. Journal of Animal Ecology 44:283-295.

Heppell, S. S., H. Caswell, and L. B. Crowder. 2000. Life histories and elasticity patterns: perturbation analysis for species with minimal demographic data. Ecology 81:654665.

Hopkins, W. A., S. E. DuRant, B. P. Staub, C. L. Rowe, and B. P. Jackson. 2006. Reproduction, embryonic development, and maternal transfer of contaminants in the amphibian Gastrophryne carolinensis. Environmental Health Perspectives 114:661-666.

Hopkins, W. A., and C. L. Rowe. 2010. Interdisciplinary and hierarchical approaches for studying the effects of metals and metalloids on amphibians. Pages 325-336 in D. Sparling, G. Linder, C. Bishoip, and S. Krest, editors. Ecotoxicology of reptiles and amphibians. SETAC Press, Pensacola, Florida, USA.

Iwasaki, Y., T. I. Hayashi, and M. Kamo. 2010. Comparison of population-level effects of heavy metals on fathead minnow (Pimephales promelas). Ecotoxicology and Environmental Safety 73:465-471.

John-Alder, H. B., and P. J. Morin. 1990. Effects of larval density on jumping ability and stamina in newly metamorphosed Bufo woodhousii fowleri. Copeia 1990:856-860.

Kalb, H. J., and G. R. Zug. 1990. Age estimates for a population of American toads, Bufo americanus (Salientia, Bufonidae), in northern Virginia. Brimleyana 16:79-86.

Karraker, N. E., J. P. Gibbs, and J. R. Vonesh. 2008. Impacts of road deicing salt on the demography of vernal poolbreeding amphibians. Ecological Applications 18:724-734.

Kimball, K. D., and S. A. Levin. 1985. Limitations of laboratory bioassays: the need for ecosystem-level testing. BioScience 35:165-171.

Lin, B. L., A. Tokai, and J. Nakanishi. 2005. Approaches for establishing predicted-no-effect concentrations for population-level ecological risk assessment in the context of chemical substances management. Environmental Science and Technology 39:4833-4840.

Linder, G., and B. Grillitsch. 2000. Ecotoxicology of metals. Pages 325-460 in D. Sparling, G. Linder, and C. A. Bishop, editors. Ecotoxicology of amphibians and reptiles. SETAC Press, Pensacola, Florida, USA.

Marian, M. P., V. Arul, and T. J. Pandian. 1983. Acute and chronic effects of carbaryl on survival, growth, and metamorphosis in the bullfrog (Rana tigra). Archives of Environmental Contamination and Toxicology 12:271-275.

Mason, R. P., J. R. Reinfelder, and F. M. M. Morel. 1996. Uptake, toxicity, and trophic transfer of mercury in a coastal diatom. Environmental Science and Technology 30:18351845.

McPeek, M. A., and B. L. Peckarsky. 1998. Life histories and the strengths of species interactions: combining mortality, growth, and fecundity effects. Ecology 79:867-879.

Miller, D. H., and G. T. Ankley. 2004. Modeling impacts on populations: fathead minnow (Pimephales promelas) exposure to the endocrine disruptor 17 beta-trenbolone as a case study. Ecotoxicology and Environmental Safety 59:1-9.

Nakamaru, M., Y. Iwasa, and J. Nakanishi. 2002. Extinction risk to herring gull populations from DDT exposure. Environmental Toxicology and Chemistry 21:195-202.

Nakamaru, M., Y. Iwasa, and J. Nakanishi. 2003. Extinction risk to bird populations caused by DDT exposure. Chemosphere 53:377-387.

Pechmann, J. H. K., D. E. Scott, R. D. Semlitsch, J. P. Caldwell, L. J. Vitt, and J. W. Gibbons. 1991. Declining amphibian populations: the problem of separating human impacts from natural fluctuations. Science 253:892-895.

Rohr, J. R., T. Sager, T. M. Sesterhenn, and B. D. Palmer. 2006. Exposure, postexposure, and density-mediated effects of atrazine on amphibians: breaking down net effects into their parts. Environmental Health Perspectives 114:46-50.

Salice, C. J., C. L. Rowe, J. H. K. Pechmann, and W. A. Hopkins. 2011. Multiple stressors and complex life cycles: insights from a population-level assessment of breeding site contamination and terrestrial habitat loss in an amphibian. Environmental Toxicology and Chemistry 30:2874-2882.

Scheuhammer, A. M., M. W. Meyer, M. B. Sandheinrich, and M. W. Murray. 2007. Effects of environmental methylmercury on the health of wild birds, mammals, and fish. Ambio $36: 12-18$.

Schmidt, B. R. 2004. Pesticides, mortality and population growth rate. Trends in Ecology and Evolution 19:459-460.

Schmidt, B. R., and B. R. Anholt. 1999. Analysis of survival probabilities of female common toads, Bufo bufo. AmphibiaReptilia 20:97-108. 
Schmidt, B. R., R. Feldmann, and M. Schaub. 2005. Demographic processes underlying population growth and decline in Salamandra salamandra. Conservation Biology 19:1149-1156.

Schmidt, B. R., W. Hodl, and M. Schaub. 2012. From metamorphosis to maturity in complex life cycles: equal performance of different juvenile life history pathways. Ecology 93:657-667.

Schmidt, B. R., M. Schaub, and B. R. Anholt. 2002. Why you should use capture-recapture methods when estimating survival and breeding probabilities: on bias, temporary emigration, overdispersion, and common toads. AmphibiaReptilia 23:375-388.

Scott, D. E. 1994. The effect of larval density on adult demographic traits in Ambystoma opacum. Ecology 75:13831396.

Semlitsch, R. D. 2003. Conservation of pond-breeding amphibians. Pages 8-23 in R. D. Semlitsch, editor. Amphibian conservation. Smithsonian Institution, Washington, D.C., USA.

Semlitsch, R. D., D. E. Scott, J. H. K. Pechmann, and J. W. Gibbons. 1996. Structure and dynamics of an amphibian community: evidence from a 16-year study of a natural pond. Pages 217-248 in M. L. Cody and J. A. Smallwood, editors. Long-term studies of vertebrate communities. Academic Press, San Diego, California, USA.

Shulse, C. D., R. D. Semlitsch, K. M. Trauth, and A. D. Williams. 2010. Influences of design and landscape placement parameters on amphibian abundance in constructed wetlands. Wetlands 30:915-928.

Sibly, R. M. 1996. Effects of pollutants on individual life histories and population growth rates. Pages 197-223 in M. E. Newman and C. H. Jagoe, editors. Ecotoxicology: a hierarchical treatment. Lewis Publishers, Boca Raton, Florida, USA.

Snodgrass, J. W., W. A. Hopkins, J. Broughton, D. Gwinn, J. A. Baionno, and J. Burger. 2004. Species-specific responses of developing anurans to coal combustion wastes. Aquatic Toxicology 66:171-182.

Snodgrass, J. W., W. A. Hopkins, B. P. Jackson, J. A. Baionno, and J. Broughton. 2005. Influence of larval period on responses of overwintering green frog (Rana clamitans) larvae exposed to contaminated sediments. Environmental Toxicology and Chemistry 24:1508-1514.

Spight, T. M. 1968. The water economy of salamanders: evaporative water loss. Physiological Zoology 41:195-203.

Stark, J. D. 2005. How closely do acute lethal concentration estimates predict effects of toxicants on populations. Integrated Environmental Assessment and Management $1: 109-113$.

Tan, S. W., J. C. Meiller, and K. R. Mahaffey. 2009. The endocrine effects of mercury in humans and wildlife. Critical Reviews in Toxicology 39:228-269.
Tanaka, Y. 2003. Ecological risk assessment of pollutant chemicals: extinction risk based on population-level effects. Chemosphere 53:421-425.

Taylor, B. E., and D. E. Scott. 1997. Effects of larval density dependence on population dynamics of Ambystoma opacum. Herpetologica 53:132-145.

Taylor, B. E., D. E. Scott, and J. W. Gibbons. 2006. Catastrophic reproductive failure, terrestrial survival, and persistence of the marbled salamander. Conservation Biology 20:792-801.

Todd, B. D. 2007. Parasites lost? An overlooked hypothesis for the evolution of alternative reproductive strategies in amphibians. American Naturalist 170:793-799.

Todd, B. D., C. M. Bergeron, M. J. Hepner, J. N. Burke, and W. A. Hopkins. 2011a. Does maternal exposure to an environmental stressor affect offspring response to predators? Oecologia 166:283-290.

Todd, B. D., C. M. Bergeron, M. J. Hepner, and W. A Hopkins. 2011b. Aquatic and terrestrial stressors in amphibians: a test of the double jeopardy hypothesis based on maternally and trophically derived contaminants. Environmental Toxicology and Chemistry 30:2277-2284.

Todd, B. D., J. D. Willson, C. M. Bergeron, and W. A. Hopkins. 2012. Do effects of mercury in larval amphibians persist after metamorphosis? Ecotoxicology 21:87-95.

Trenham, P. C., and H. B. Shaffer. 2005. Amphibian upland habitat use and its consequences for population viability. Ecological Applications 15:1158-1168.

Unrine, J. M., C. H. Jagoe, W. A. Hopkins, and H. A. Brant. 2004. Adverse effects of ecologically relevant dietary mercury exposure in southern leopard frog (Rana sphenocephala) larvae. Environmental Toxicology and Chemistry 23:29642970.

Vincent, S. E., B. R. Moon, R. Shine, and A. Herrel. 2006. The functional meaning of "prey size" in water snakes (Nerodia fasciata, Colubridae). Oecologia 147:204-211.

Vonesh, J. R., and O. De la Cruz. 2002. Complex life cycles and density dependence: assessing the contribution of egg mortality to amphibian declines. Oecologia 133:325-333.

Weiner, J. G., and D. J. Spry. 1996. Toxicological significance of mercury in freshwater fish. Pages 297-340 in W. N. Beyer, G. H. Heinz, and A. W. Redmon-Norwood, editors. Environmental contaminants in wildlife: interpreting tissue concentrations. Lewis Publishers, Boca Raton, Florida, USA.

Wilbur, H. M. 1977. Density-dependent aspects of growth and metamorphosis in Bufo americanus. Ecology 58:196-200.

Wilbur, H. M. 1980. Complex life-cycles. Annual Review of Ecology and Systematics 11:67-93.

Willson, J. D., and W. A. Hopkins. 2011. Prey morphology constrains the feeding ecology of an aquatic generalist predator. Ecology 744-754. 